\title{
Review \\ Current Surgical Management Strategies for Colorectal Cancer Liver Metastases
}

\author{
Gabriel D. Ivey ${ }^{1}$, Fabian M. Johnston ${ }^{1}$, Nilofer S. Azad ${ }^{2}$, Eric S. Christenson ${ }^{2}$, Kelly J. Lafaro ${ }^{1,+}$ \\ and Christopher R. Shubert ${ }^{1, *,+}$
}

1 Department of Surgery, Sidney Kimmel Comprehensive Cancer Center, Johns Hopkins University School of Medicine, Baltimore, MD 21205, USA; igabrie2@jhmi.edu (G.D.I.); fjohnst4@jhmi.edu (F.M.J.); klafaro1@jhmi.edu (K.J.L.)

2 Department of Medical Oncology, Sidney Kimmel Comprehensive Cancer Center, Johns Hopkins University School of Medicine, Baltimore, MD 21205, USA; nazad2@jhmi.edu (N.S.A.); echris14@jhmi.edu (E.S.C.)

* Correspondence: christopher.shubert@jhu.edu

+ These authors contributed equally to this work.

Citation: Ivey, G.D.; Johnston, F.M.; Azad, N.S.; Christenson, E.S.; Lafaro, K.J.; Shubert, C.R. Current Surgical Management Strategies for Colorectal Cancer Liver Metastases. Cancers 2022, 14, 1063. https://doi.org/ 10.3390/cancers14041063

Academic Editor:

Damián García-Olmo

Received: 25 January 2022

Accepted: 18 February 2022

Published: 20 February 2022

Publisher's Note: MDPI stays neutral with regard to jurisdictional claims in published maps and institutional affiliations.

Copyright: (C) 2022 by the authors. Licensee MDPI, Basel, Switzerland. This article is an open access article distributed under the terms and conditions of the Creative Commons Attribution (CC BY) license (https:// creativecommons.org/licenses/by/ $4.0 /)$.
Simple Summary: Colorectal cancer is one of the most common cancer diagnoses in the world. At least half of patients diagnosed with colorectal cancer will develop metastatic disease, with most being identified in the liver. Surgical resection of colorectal liver metastases (CRLM) is potentially curative. Surgical resection of CRLM, however, remains underutilized despite the continued expansion of operative strategies available. This is likely due to differing views on resectability. Resectability is a surgical assessment, and the classification of CRLM as unresectable should only be made by an experienced hepatobiliary surgeon. Obtaining a surgical evaluation at the time of liver metastasis discovery may help mitigate the challenge of assessing resectability and the determination of potential operative time windows within current multimodal management strategies. The aim of this review is to help facilitate discussions surrounding resectability as well as the timing and sequencing of both surgical and non-surgical therapies.

Abstract: Colorectal cancer is the third most common cancer diagnosis in the world, and the second most common cause of cancer-related deaths. Despite significant progress in management strategies for colorectal cancer over the last several decades, metastatic disease remains difficult to treat and is often considered incurable. However, for patients with colorectal liver metastases (CRLM), surgical resection offers the best opportunity for survival, can be curative, and remains the gold standard. Unfortunately, surgical treatment options are underutilized. Misperceptions regarding resectable and unresectable CRLM likely play a role in this. The assessment of factors that impact resectability status like medical fitness, technical considerations, and disease biology can be difficult, necessitating careful multidisciplinary input and discussion. The identification of ideal operative time windows that align with the multimodal management of these patients can also be perplexing. For all patients with CRLM it may therefore be advantageous to obtain surgical evaluation at the time of discovering liver metastases to mitigate these challenges and minimize the risk of undertreatment. In this review we summarize current surgical management strategies for CRLM and discuss factors to be considered when determining resectability.

Keywords: colorectal liver metastases; parenchymal-sparing hepatectomy; one- and two-stage hepatectomy; associating liver partition and portal vein ligation for staged hepatectomy; liver transplantation; hepatic arterial infusional chemotherapy; minimally invasive liver resection

\section{Introduction}

Colorectal cancer is the third most common cancer diagnosis in the world [1], and the second most common cause of cancer-related deaths [2]. Over the last several decades we have seen significant progress in management strategies for colorectal cancer; screening 
modalities have improved [3], new systemic treatment options have lengthened survival [4], and recent developments in surgical management strategies have expanded resection eligibility criteria [5,6]. Despite this progress, metastatic disease remains the most common cause of death [7]. Metastatic disease, however, is not a contraindication to surgical intervention. For those who develop metastatic disease to the liver, resection of this disease is associated with a $20 \%$ cure rate [8], and five-year survival rates can exceed 50\% [9].

Unfortunately, surgical management strategies for colorectal liver metastases (CRLM) remain underutilized [10]. Misperceptions, even among surgeons, regarding resectable and unresectable CRLM likely play a role in this [11-13]. The assessment of factors that impact resectability status like medical fitness, technical considerations, and disease biology can be difficult. The identification of ideal operative time windows that align with the multimodal management of these patients can also be perplexing. Most patients who have CRLM are seen by medical oncologists for consideration of systemic therapy for management of their metastatic disease, often placing the burden of assessing resectability on medical oncologists alone [10]. To facilitate optimal management all patients with CRLM should have a surgical evaluation at the time of liver metastasis discovery, prior to any treatment decision [14,15], and preferably in the setting of a multidisciplinary conference [16].

The treatment of resectable CRLM traditionally began with chemotherapy and included liver resection as a later option depending on response to systemic treatment. For select patients with resectable CRLM, however, a surgery-first approach may be advantageous [17], and we have recently seen the benefit of perioperative chemotherapy come into question $[18,19]$. Additionally, there are numerous locoregional therapies for which all patients with CRLM, including those with extrahepatic disease, should be considered [20,21].

While it is difficult to assess a causal relationship between multidisciplinary care and improvement in patient survival [22], it has been suggested that changes in treatment recommendations for patients with gastrointestinal malignancies occur at least one third of the time after multidisciplinary evaluation [23]. For patients with CRLM, it is speculated that at least $20 \%$ of patients with isolated liver metastases who have been advised to undergo a chemotherapy-first approach may instead be eligible for upfront surgery [16]. Longitudinal multidisciplinary care of patients with CRLM, including those patients with extrahepatic disease, has the potential to improve overall survival (OS) when compared to systemic therapy alone by increasing resectability and resection rates [24].

In this review we summarize current surgical management strategies for CRLM and discuss factors considered when determining resectability with which all oncology providers should be familiar. Recent trials evaluating the efficacy of current resection techniques are discussed. Systemic treatment strategies are not examined in detail. Ablative locoregional therapies are not reviewed.

\section{Assessment of Resectability}

Classically, patients with CRLM are deemed as having "resectable" or "unresectable" disease with some groups further stratifying patients into a third group called "potentially resectable" or "borderline". The exact definition of each classification varies across the literature, making comparisons between studies difficult. Despite this, multidisciplinary teams should attempt to define a patient's resectability for the purposes of treatment planning. Considerations when assessing resectability include an evaluation of disease burden (i.e., size, number, and distribution of CRLM) [25-27], impression of disease biology (i.e., rate of disease progression, suspicion of extrahepatic disease, timing of appearance with relationship to the primary colorectal tumor, primary colorectal tumor sidedness, RAS/BRAF mutation status, microsatellite instability [MSI] status) [28,29], and technical aspects like relationship to vascular inflow, outflow, and biliary drainage [11]. In Table 1 we list working definitions for these resectability classifications. 
Table 1. Definitions of common colorectal liver metastases resectability classifications.

\begin{tabular}{ll}
\hline Resectability Classification & \multicolumn{1}{c}{ Definition } \\
\hline Resectable & $\begin{array}{l}\text { The CRLM can be completely resected, two adjacent } \\
\text { liver segments can be spared, adequate vascular } \\
\text { inflow and outflow and biliary drainage can be } \\
\text { preserved, and the volume of the future liver remnant } \\
\text { will be adequate (i.e., at least 20\% of the total } \\
\text { estimated liver volume) [30]. }\end{array}$ \\
& $\begin{array}{l}\text { The CRLM can potentially be completely resected, but } \\
\text { there may be technical (i.e., odds of achieving an } \text { R0 }\end{array}$ \\
& $\begin{array}{l}\text { resection are reduced) and/or biological challenges } \\
\text { (i.e., numerous liver metastases, evidence of disease } \\
\text { progression, possible extrahepatic disease) [31]. }\end{array}$ \\
\hline Borderline & $\begin{array}{l}\text { The CRLM cannot be resected due to burden of } \\
\text { disease (i.e., greater than } 70 \% \text { of the liver involved or } \\
\text { more than six segments, invasion of both portal veins } \\
\text { or all hepatic veins) [32]. }\end{array}$ \\
\hline Unresectable &
\end{tabular}

CRLM, colorectal liver metastases.

Surgery for CRLM is always performed with curative intent; there is no role for debulking surgery [33]. In this regard, surgical planning revolves around strategizing for the full removal of the tumor while preserving a sufficient remnant of healthy liver tissue (future liver remnant [FLR]) to limit the risk of postoperative liver dysfunction/failure [34]. Resection of disappearing liver metastases should be included in this plan, as more than half of these lesions will recur if left in situ [35-37]. Microscopic residual disease is found in up to $90 \%$ of specimens harboring radiologically occult liver metastases [38-40]. Due to the liver's enormous regenerative capacity, as much as $80 \%$ of a healthy, noncirrhotic liver can be removed [26]. A number of factors, however, like cirrhosis, fibrosis, cholestasis, steatosis, and steatohepatitis can impair the liver's regenerative capacity [41]. Many commonly used chemotherapeutics, like 5-fluorouracil, irinotecan, and oxaliplatin are known to damage hepatocytes, and their use is often associated with the development of the aforementioned liver injuries [42]. Goal FLR is subsequently dependent on the quality of liver parenchyma. Current guidelines for extended hepatectomies recommend an FLR of $\geq 20-25 \%$ in healthy patients, $>30 \%$ in patients with chemotherapy-associated liver injury, and $>40 \%$ in cirrhotics [43].

Preoperative planning therefore requires high-quality liver specific imaging in order to properly assess disease burden and FLR. Computed tomography (CT), magnetic resonance imaging (MRI), and positron emission tomography (PET) are the commonly used modalities for CRLM. Many centers consider modern CT techniques equivalent to MRI, with MRI being helpful for adjudicating indeterminate hepatic lesions [44]. Several recent studies, however, suggest MRI to have higher sensitivity and specificity for CRLM $[45,46]$. PET is considered a helpful adjunct in select scenarios. Some centers consider PET imaging for further evaluation of indeterminate nodules or soft tissue masses identified on CT or MRI [44]. Others consider PET for patients with an elevated carcinoembryonic antigen (CEA) level, but unremarkable CT or MRI cross-sectional imaging [44]. In one randomized trial that investigated the impact of preoperative PET vs. CT without PET, the use of PET imaging did not frequently change surgical management or have an association with improved survival [47].

Following obtainment of high-quality liver protocol imaging, FLR can be measured using 3-D volumetric software. Three-dimensional volumetric analysis and planning of major liver resections is now standard for some centers as 3-D analysis generates FLR calculations while allowing recognition of and accommodation for intrahepatic anatomical variants, adjustment for tumor volume, and further tailoring for increasingly complex resection strategies. 
If the FLR is inadequate to allow for safe resection, but the patient is fit enough for surgery, FLR can be augmented using a variety of techniques (i.e., portal vein embolization, two-stage hepatectomy, associating liver partition and portal vein ligation for staged hepatectomy). Discussions of these strategies are in select sections that follow. Similarly, resectability is not static. For patients with initially unresectable CRLM, chemotherapy has the potential to convert such disease to resectable [48], and can be administered with or without hepatic arterial infusional chemotherapy [49].

\section{Treatment Sequencing}

CRLM represents a spectrum of disease that can present in a variety of manners. Although exact definitions vary, synchronous CRLM are liver metastases that are discovered at or before diagnosis of the primary colorectal tumor [50]. Approximately 14-25\% of patients diagnosed with colorectal cancer will be identified with synchronous disease [51-54]. Colorectal metastases discovered after diagnosis or resection of the primary colorectal tumor are considered metachronous CRLM [50]. About 7-30\% of patients with colorectal cancer will develop metachronous disease [51-54]. These groupings assist in determining the order of treatment strategies and sequencing [55].

\subsection{Synchronous CRLM}

For patients with resectable or borderline resectable synchronous CRLM, three treatment approaches exist: classic, combined, and reversed [56]. Upfront chemotherapy with or without additional radiotherapy for primary rectal tumors is an option for each of these three treatment strategies and should be carefully discussed and decided upon in multidisciplinary fashion. The classic approach sequences surgery for the primary colorectal tumor, followed by adjuvant chemotherapy and then hepatic resection. The combined approach is a combined liver and colorectal resection followed by adjuvant chemotherapy. The reverse approach sequences surgery for the liver metastases, followed by adjuvant chemotherapy and then resection of the primary colorectal tumor.

Determination of an appropriate treatment strategy is dependent on patient fitness, the burden of disease, and institutional experience. For instance, patients with CRLM who have a bleeding or obstructing primary colorectal tumor require more urgent surgical management of their primary colorectal tumor in terms of resection or fecal diversion prior to chemotherapy and liver resection. There are also variants. It is the preference of some surgeons to offer a two-stage hepatectomy where during the first-stage hepatectomy the primary colorectal tumor is also addressed, followed by additional chemotherapy, and ultimately the second-stage hepatectomy. Some institutions prefer to manage both the primary and the CRLM in a single surgery when patient fitness allows.

The treatment paradigm for synchronous CRLM has traditionally always been a chemotherapy-first approach. However, as just described, several treatment sequencing options should be considered for all patients with CRLM when appropriate, including a liver-first approach with or without neoadjuvant chemotherapy. Data supporting this strategy are growing and have demonstrated reasonable short- and long-term outcomes [17,57-59]. First proposed in 2006 [58], it is an appealing treatment approach as it focuses attention on the most prognostically important site of disease-the liver. Additionally, should chemotherapy not be administered prior to resection, concerns brought about by chemotherapy-associated liver injury can be avoided (i.e., sinusoidal injury, steatosis), potentially resulting in improved outcomes and the need for a smaller FLR.

Recent evidence suggests that of the surgical sequencing options available for patients with CRLM, a liver-first approach should likely be favored in appropriately selected patients. The findings of a recently published retrospective, propensity-matched study that evaluated 7360 patients with synchronous CRLM revealed that in patients with solitary and multiple unilobar CRLM, survival was similar regardless of treatment strategy (classic, $n=4415$; combined, $n=2393$; reversed, $n=552$ ). In patients with multiple bilobar metastases, however, a liver-first approach was associated with improved overall survival 
(3-year OS 69\% vs. classic approach 60.4\%, $p=0.031$; vs. combined 54.4\%, $p=<0.001$ ) [17]. Compared with the other groups, the liver-first cohort had more rectal tumors (58\% vs. $31.2 \%$ ), a higher tumor burden, and were more likely to receive neoadjuvant chemotherapy $(75 \%)$ [17]. These findings highlight the nuances that must be considered when assessing treatment options for patients with CRLM and the benefit of early surgeon involvement.

\subsection{Metachronous CRLM}

For patients with resectable or borderline resectable metachronous disease, treatment approaches are much simpler compared to synchronous disease: surgery alone or surgery with perioperative chemotherapy [60]. There are numerous variants within the perioperative chemotherapy approach. It is the preference of some providers to administer chemotherapy before surgical intervention, after surgical intervention, or both before and after.

\subsection{Systemic Chemotherapy Sequencing}

Both synchronous and metachronous CRLM have traditionally been treated with perioperative chemotherapy, but the benefits of this management strategy have recently come under scrutiny. Results from two randomized controlled trials that evaluated the effectiveness of surgery alone versus surgery with perioperative chemotherapy in patients with synchronous and metachronous CRLM suggest that while perioperative chemotherapy may improve progression-free survival (PFS) or disease-free survival (DFS), there does not seem to be a benefit in OS [18,19]. These findings are also clinically significant as treatment with FOLFOX (folinic acid, fluorouracil, and oxaliplatin), the chemotherapy strategy used in each of these studies, places patients at risk for chemotherapy-related toxicities and adverse events. One well-recognized phenomenon, for instance, is that of chemotherapy-induced peripheral neuropathy, which can substantially affect quality of life [61].

In the European Organisation for Research and Treatment of Cancer (EORTC) 40983 trial, the authors investigated the impact of FOLFOX on PFS and OS in patients with resectable CRLM and up to four liver metastases. A total of 364 patients with resectable CLRM were randomized to either perioperative FOLFOX 4 or surgery alone. Just over $50 \%$ of enrolled patients had primary colon cancer, about $60 \%$ had metachronous disease, and a majority had either one or two liver metastases. Patients in the perioperative chemotherapy arm experienced improved three-year PFS (36.2 percent vs. 28.1 percent, $p=0.041$ ) at the expense of increased postoperative complications ( $25 \%$ vs. $16 \%, p=0.04)$ [60]. No difference in OS was observed between the two cohorts (61.3 vs. 54.3 months), although the trial was not powered upfront to detect a difference in OS [18].

In the Japan Clinical Oncology Group Study (JCOG0603) trial, the authors investigated the impact of FOLFOX on DFS and OS in patients with any number of CRLM. A total of 300 patients were randomly assigned to either hepatectomy alone or hepatectomy followed by mFOLFOX6. The trial was notably terminated early at the third interim analysis per protocol because DFS was significantly longer in patients treated with hepatectomy followed by chemotherapy (49.8\% vs. $38.7 \%$ at 5 years, $p=0.006$ ) [19]. Just over $75 \%$ of enrolled patients had primary colon cancer, about $45 \%$ had metachronous disease, and approximately 90\% had 1-3 liver metastases [19]. No difference in postoperative complications or 5-year OS (hepatectomy alone $83.1 \%$ vs. $71.2 \%, p=0.42$ ) was observed between the two cohorts [19].

Taken together, these studies highlight the wealth of information available on current treatment strategies for CRLM that we must carefully discuss with our patients when determining a treatment approach. Benefits in DFS and PFS for patients are not insignificant, but they can easily be misperceived as benefits in overall survival [62]. The data on management strategies surrounding metachronous and synchronous CRLM are vast and there is no one-size-fits-all when it comes treatment strategy, including the selection of a surgical approach. Discussions with patients regarding potential surgical intervention must also be carefully framed and communicated. While surgical interventions have the 
potential to provide benefit to a select cohort, they are not without morbidity and mortality risks that must be carefully weighed.

\subsection{Considerations When Sequencing Chemotherapy before Hepatectomy}

Should chemotherapy be administered prior to hepatectomy, careful consideration should be given to the duration of chemotherapy administration and the potential liverspecific injuries that can result.

It has been suggested that for patients with resectable CRLM, resection should be considered after 2-4 months of chemotherapy so long as there is no evidence of disease progression [63]. In one single institution study, it was observed that for patients treated with chemotherapy alone or HAIC combined with systemic chemotherapy, additional tumor response was not appreciated beyond 4 months in either group [63]. Similar findings were observed in another single-institutional study that examined 407 patients with CRLM who underwent hepatectomy after neoadjuvant chemotherapy [64]. The authors of this study observed the optimal duration of neoadjuvant chemotherapy to be 5 cycles or less, and that treatment beyond 5 cycles was not associated with significant differences in R0 resection rates, pathological response, or postoperative complications. Receipt of greater than 5 cycles of neoadjuvant chemotherapy was also observed on multivariate analysis to be associated with reduced PFS ( $\mathrm{HR}=1.808,95 \%$ CI $1.205-2.712, p=0.004)$ and OS (HR 1.723, 95\% CI 1.041-2.851, $p=0.034$ ).

In addition to duration of chemotherapy administered, regimen is also of significance when assessing the sequelae of chemotherapy. Liver injury is regimen-specific, with oxaliplatin-based regimens often associated with sinusoidal injury and irinotecan-based regimens often associated with steatohepatitis [65]. These impairments have the potential to impact surgical morbidity and mortality [66,67]. In the EORTC 40983 trial, patients in the perioperative chemotherapy arm experienced more postoperative complications than those in the surgery-alone arm $(25 \%$ vs. $16 \%, p=0.04)$ [60]. No differences in mortality were observed. Interestingly, in the JCOG0603 trial, the incidence of perioperative complications between arms was similar [19]. However, one patient died of unknown cause after 3 courses of neoadjuvant mFOLFOX6.

\section{Surgical Management Strategies}

Once an assessment of medical fitness has been established, and a treatment sequencing approach selected, there are several hepatic resection operations for CRLM (Figure 1) that can be considered. This recently expanded selection of surgical approaches is the direct result of improved understanding of segmental anatomy [68], the importance of inflow occlusion (i.e., Pringle maneuver) [69], and low central venous pressure anesthesia [70]. Operations offered to patients must be individualized with the goal of performing a complete resection of all radiographically visible disease (including disappearing liver metastases given the risk of recurrence) [36,38], maximizing FLR, and preserving vascular inflow, outflow, and biliary drainage.

\subsection{Parenchymal-Sparing Hepatectomy}

Parenchymal-sparing hepatectomy, also called non-anatomic liver resection(s), relies on the principal of preserving non-tumorous liver tissue. Tumors are resected with as little normal hepatic parenchyma as possible without the need for pre-operative techniques to induce liver hypertrophy, like portal vein embolization (PVE), portal vein ligation (PVL), or liver venous deprivation (LVD). Indications for this technique include unilobar and bilobar disease.

This technique is considered oncologically equivalent to anatomic or major liver resections, and is associated with lower postoperative morbidity and shorter hospital stays [71]. Use of this technique does not increase the risk of recurrence in the liver remnant, and in fact allows for easier salvage therapy in case of liver recurrence [72]. Because of this it is considered the preferred method for the treatment of resectable CRLM, if allowed by tumor size and location [71]. 


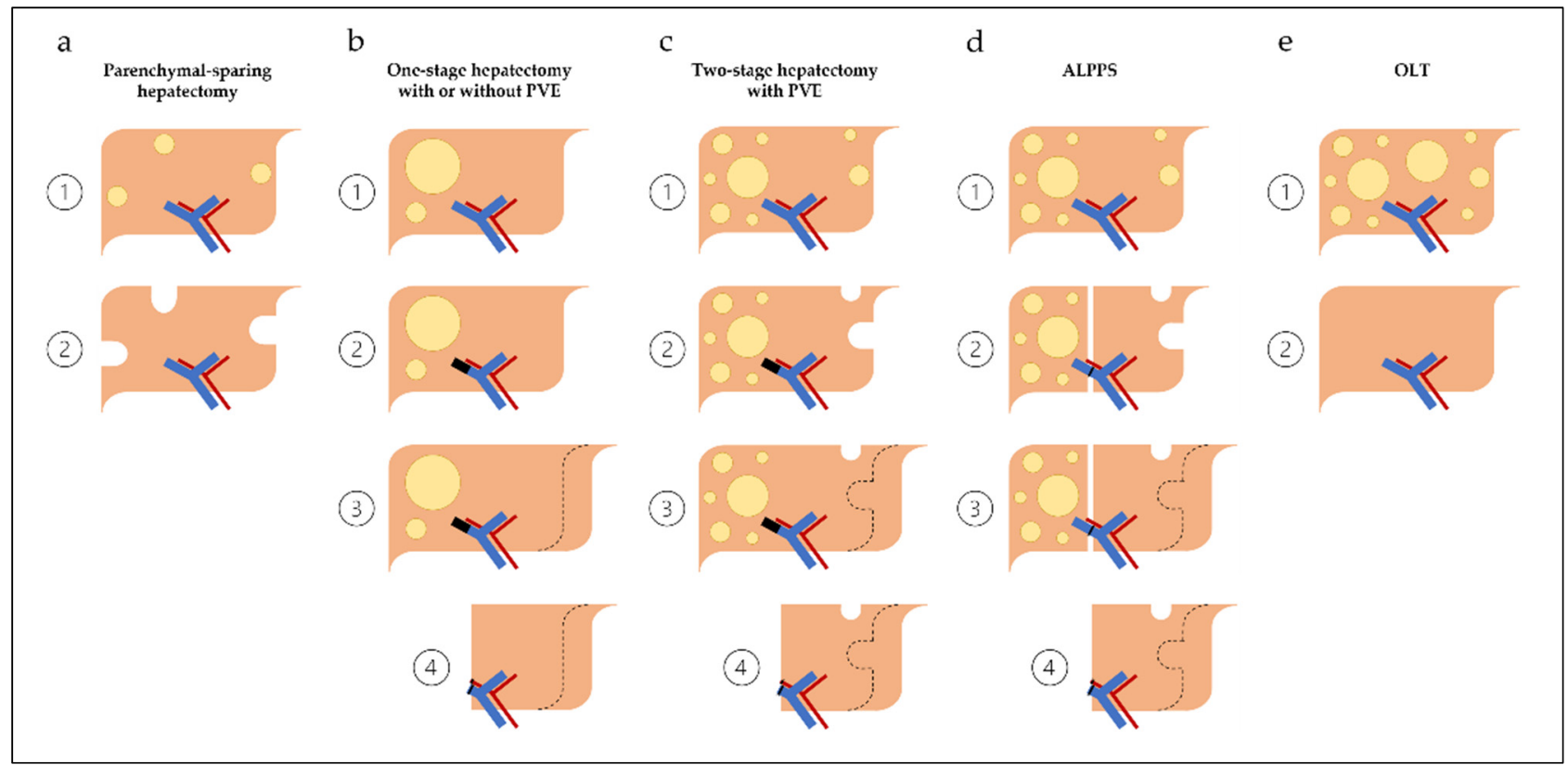

Figure 1. Surgical strategies for colorectal liver metastases. (a) Parenchymal-sparing hepatectomy. (b) One-stage hepatectomy with or without PVE. (c) Two-stage hepatectomy with PVE. (d) Associating liver partition and portal vein ligation for staged hepatectomy (ALPPS). (e) Orthotopic liver transplantation (OLT). Dashed lines illustrate the future liver remnant prior to augmentation (i.e., PVE; portal vein ligation during ALPPS).

Some centers employ extreme parenchymal-sparing techniques as repeat hepatectomy for recurrent CRLM can be safely performed in select patients [73]. Recurrence in the residual liver occurs approximately 33\% of the time [18], and if maximal normal parenchyma was not spared during the initial hepatectomy, the odds of successfully performing a repeat hepatectomy are significantly reduced. Extreme parenchymal-sparing techniques employ ultrasound for performance of vessel-guided hepatectomy. In select centers, outcomes are comparable to that of alternative surgical management strategies like two-stage hepatectomy (TSH) and associating liver partition and portal vein ligation for staged hepatectomy (ALPPS) for patients with multiple, bilobar, deeply located CRLM [74,75].

Parenchymal-sparing hepatectomy can be performed in the classic, combined, or reversed approaches for synchronous disease or alone (with or without perioperative systemic therapy) for metachronous disease.

\subsection{One-Stage Hepatectomy with or without PVE/HVE}

One-stage hepatectomy is a liver resection that is performed with or without preoperative techniques to induce hypertrophy of the FLR. Should pre-operative hypertrophy be required due to a small FLR (i.e., <30\%), PVE with or without hepatic vein embolization (HVE) can be performed. Following sufficient hypertrophy, hepatectomy can then be performed. Disease in patients undergoing one-stage hepatectomy can be multifocal, and this strategy can be combined with parenchymal-sparing hepatectomy of the FLR if disease is bilobar. Patients with bilobar disease who require hypertrophy of the FLR, however, are typically not managed via one-stage hepatectomy.

Historically, one-stage hepatectomy for patients with CRLM was considered superior to parenchymal-sparing hepatectomy [76], but several studies have now shown parenchymal-sparing techniques to be oncologically equivalent and associated with lower morbidity and mortality [71,77]. One-stage hepatectomy strategies are therefore preferred only in select circumstances and usually related to anatomy and/or tumor burden [44]. 
One-stage hepatectomy can be performed in the classic, combined, or reversed approaches for synchronous disease or alone (with or without perioperative systemic therapy) for metachronous disease.

\subsection{Two-Stage Hepatectomy}

A two-stage hepatectomy is a sequential liver resection where during the first operation the planned FLR is surgically cleared of disease. Following tumor clearance from the FLR, the contralateral portal vein is either ligated or embolized to promote hypertrophy of the FLR. Once sufficient hypertrophy has been achieved, the second liver resection removes the remaining diseased liver.

This strategy takes advantage of the liver's regenerative capacity allowing patients with significant bilobar disease a chance at cure. Use of this technique has grown exponentially since 2000, when the first series of two-stage hepatectomy in patients with unresectable bilateral CRLM was published [78]. Results from the largest two-stage hepatectomy series in the US, published in 2021, demonstrate it to be a safe and feasible procedure for patients with bilobar disease [79]. Among the 196 patients who underwent two-stage hepatectomy in this series for a median number of 7 tumors, median OS was 50 months [79]. PVE was performed in $128(65.3 \%)$ patients and a majority of patients received chemotherapy prior to the first stage than after the second stage $(92 \%$ vs. $60 \%$, $p=0.308)$ [79].

Two-stage hepatectomy is more commonly performed in the combined or reversed approaches for synchronous disease or alone (with or without perioperative systemic therapy) for metachronous disease. When combined resection for synchronous disease is chosen, the resection of the primary colorectal cancer is typically performed at the time of first-stage liver resection.

\subsection{Associating Liver Partition and Portal Vein Ligation for Staged Hepatectomy (ALPPS)}

An associating liver partition and portal vein ligation for staged hepatectomy (ALPPS) procedure is a two-stage hepatectomy variant. Like the conventional two-stage hepatectomy, the goal of the first operation is to clear the planned FLR of disease. Following this, the contralateral portal vein is ligated and the right and left hemilivers are divided without disturbance to the remaining vascular and biliary pedicles. Once sufficient hypertrophy is achieved, which typically occurs at a faster rate compared to PVE, the second liver resection removes the remaining diseased liver.

When performed at experienced centers in well-selected patients, there are data that suggest it to be superior to two-stage hepatectomy $[5,80]$. In a cohort of 100 patients with CRLM and standardized FLR (sFLR) $<30 \%$ who were randomized to either ALPPS or two-stage hepatectomy, patients randomized to ALPPS had a higher resection rate $(92 \%$ vs. $80 \%, p=0.091$ ), and improved OS (46 vs. 26 months, $p=0.028$ ) without differences in complications ( $43 \%$ vs. $43 \%, p=0.99)$, 90-day mortality $(8.3 \%$ vs. $6.1 \%, p=0.68)$, or R0 resection rates $(77 \%$ vs. $57 \%, p=0.11)[5,80]$.

ALPPS is most commonly performed in the combined approach for synchronous disease or alone (with or without perioperative systemic therapy) for metachronous disease. When combined resection for synchronous disease is chosen, the resection of the primary colorectal cancer is typically performed at the time of first-stage liver resection.

\subsection{Liver Transplantation}

Orthotopic liver transplantation (OLT) removes the entire diseased liver and replaces it with a normal liver (partial or whole) from a deceased or living donor. It is a very rare procedure performed for CRLM, but mounting evidence mainly from European centers with large donor pools [81] suggests that it may provide survival benefit for select patients [6]. The trialing of transplantation as a potential strategy for patients with CRLM has been the result of continued recurrence risk following curative intent liver resection. As 
many as two-thirds of patients undergoing curative intent liver resection will experience disease recurrence, half of which occurs in the remnant liver [18].

The tractability of this approach outside of select institutions with large donor pools and significant experience remains to be seen. The global transplant community continues to face a shortage of organs [82], and current indications for OLT for patients with CRLM are not well-defined [81]. Experience with OLT at Oslo University Hospital in Norway between 2006 and 2019 suggests that transplant for patients with unresectable colorectal metastases and left-sided primary tumors have improved 5-year OS compared to PVE and liver resection $(45.3 \%$ vs. $12.5 \%, p=0.04)$ [6].

Other important poor prognostic features that should be considered when evaluating transplant candidacy in addition to right-sided disease are BRAF and RAS mutational status, progression on chemotherapy, and N2 nodal status of the primary. Transplantation is not recommended for patients with BRAF V600E mutations but can be considered for patients with RAS mutations despite their poor prognostic association [83]. Transplantation is not recommended if there is evidence of radiological or biochemical progression of disease during the 6 months of required bridging therapy [83]. Nodal disease of N2 of the primary tumor is a relative exclusion criterion [83].

\subsection{Hepatic Arterial Infusional Chemotherapy}

Hepatic arterial infusional chemotherapy (HAIC) is an additional surgical and chemotherapeutic management strategy that should be considered in patients with CRLM (Figure 2). Utilization of this strategy requires subcutaneous placement of a hepatic arterial infusional pump (HAIP) - a metallic device about the size of a hockey puck. Connected to this device is a catheter, which during placement is inserted into the gastroduodenal artery, allowing direct arterial access for the administration of agents with high first-pass hepatic extraction (i.e., floxuridine [FUDR]) limiting systemic toxic side effects, and allowing for the concomitant administration of systemic chemotherapy $[84,85]$. While it is not a liver resection strategy, it can be placed following hepatectomy for adjuvant liver-directed chemotherapy [86,87]. Traditionally, however, it has often been used as a strategy to convert patients with initially unresectable CRLM to resectable [88].

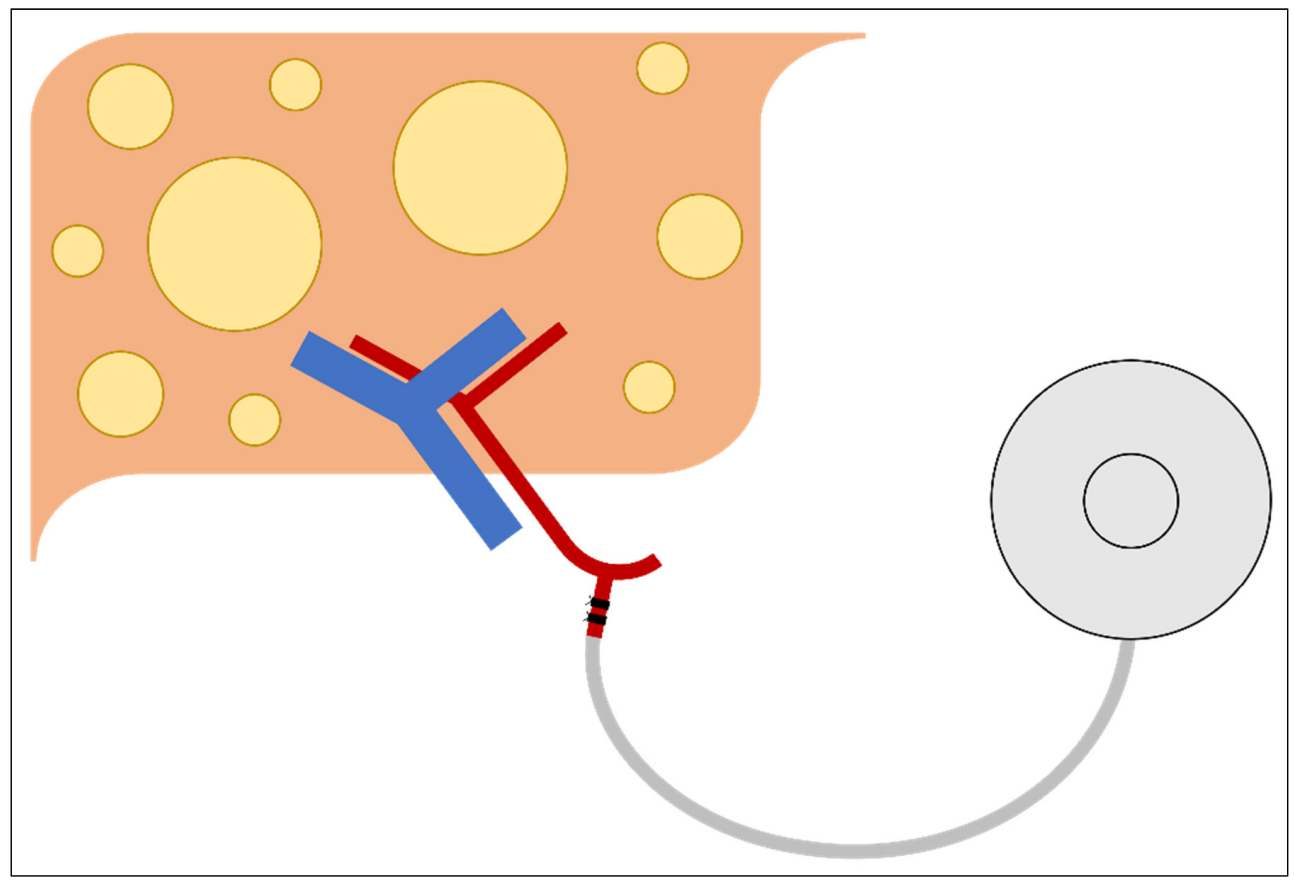

Figure 2. Hepatic arterial infusional pump. 
The pairing of HAIC with systemic chemotherapy has the potential to significantly augment response rates for patients with initially unresectable CRLM. Objective response rates for this cohort following the administration of systemic therapy alone are around $64 \%$ (range, $43-79 \%$ ), generating resection rates of about $23 \%$ [89]. When systemic therapy is administered concomitantly with HAIC, objective responses as high as $85 \%$ have been observed in patients who have previously received chemotherapy [90], and as high as 100\% in chemotherapy naïve patients [91]. Rates of conversion to resectability following this combination have been reported as high as 52\% [92].

The expanded use of this modality has been hindered by the specialized expertise needed for pump placement, use, and maintenance. Patients with HAIPs must return for follow-up visits every 2 weeks in order to maintain the reservoir system, treatment facilities must be able to manage complications that can occur following placement (i.e., port migration, catheter dislocation, arterial occlusion, etc.), and chemotherapy-administering teams must know how to properly access the pump, troubleshoot malfunctions, and manage toxicities associated with combined HAIC and systemic chemotherapy $[86,93,94]$.

\subsection{Repeat Hepatectomy for Recurrence}

Hepatic recurrence following curative intent hepatectomy for CRLM occurs approximately $33 \%$ of the time [18]. For select patients, repeat hepatectomy is associated with improved OS if there is a sufficient remnant of healthy liver tissue $[95,96]$. Ahmed et al. examined 274 consecutive patients who underwent resection of CRLM, of which 64 developed metastases confined to the liver. Five-year OS was significantly higher for the 19 patients who underwent repeat hepatectomy compared to the 45 patients who did not $(73 \%$ vs. $43 \%, p=0.03)$ [95]. Factors predictive of worse OS identified on multivariate analysis were time interval less than 1 year between resection of the primary colorectal tumor and liver resection $(p=0.001)$, more than 3 CRLM $(p=0.001)$, no repeat hepatectomy $(p=0.01)$, and lymph node-positive colorectal cancer $(p=0.02)$.

In another study by Battula at al. that examined 969 patients who underwent hepatic resection for CRLM at a single institution over a 13-year period, repeat hepatectomy was also observed to be associated with improved long-term survival in a select cohort [96]. For the 53 patients who were identified as having undergone a repeat hepatectomy, 5-year OS was observed to be $52 \%$. Factors predictive of worse OS identified on Cox regression analysis were R1 resection at first hepatectomy $(p=0.002)$, short time interval between the first and second hepatectomies $(p=0.02)$, and the presence of extrahepatic disease $(p=0.02)$.

\section{Minimally Invasive Liver Resection}

In experienced centers, laparoscopic and robotic surgery for CRLM is safe and capable of providing equivalent oncologic outcomes compared to open approaches [97-99]. The option of a minimally invasive approach is a possibility for most open cases, albeit with greater difficulty depending on the size and location of the CRLM [99]. Like other minimally invasive operations that have been compared to their open counterparts, minimally invasive liver resection is also often associated with lower blood loss and shorter hospital stay [100]. Combined minimally invasive colorectal and liver excision surgery is also feasible and safe but requires an expert surgical team in both minimally invasive colorectal and liver surgery [101].

\section{Conclusions}

Surgical resection of CRLM remains the gold standard and the best opportunity for long-term survival. For a select cohort of patients with CRLM, surgical resection can be curative. Refinements in the understanding of surgical anatomy along with surgical technique have resulted in an expanded assortment of available surgical approaches and have expanded what is considered resectable.

Surgical management strategies, however, remain underutilized despite this progress, likely the result of misperceptions surrounding resectability. Size, number, and distribution 
of CRLM can be prognostic, along with the presence of extrahepatic disease, but carefully selected and sequenced multimodal treatment strategies can result in improved survival, including surgery-first approaches. Early, upfront, and prospective involvement of a surgeon with knowledge and experience in liver surgery should be considered following the diagnosis of CRLM in order to minimize the risk of undertreatment.

Author Contributions: G.D.I. wrote the initial draft; F.M.J., N.S.A., E.S.C., K.J.L., and C.R.S. revised and edited the manuscript. All authors have read and agreed to the published version of the manuscript.

Funding: This research received no external funding.

Conflicts of Interest: The authors declare no conflict of interest.

\section{References}

1. International Agency for Research on Cancer, W.H.O. Estimated Number of New Cases in 2020, Worldwide, Both Sexes, All Ages. 2020. Available online: https:/ /gco.iarc.fr/ (accessed on 7 November 2021).

2. International Agency for Research on Cancer, W.H.O. Estimated Number of Deaths in 2020, Worldwide, Both Sexes, All Ages. 2020. Available online: https:/ / gco.iarc.fr/ (accessed on 7 November 2021).

3. Kanth, P.; Inadomi, J.M. Screening and prevention of colorectal cancer. BMJ 2021, 374, n1855. [CrossRef]

4. Lee, H.Y.; Woo, I.S. Perioperative Systemic Chemotherapy for Colorectal Liver Metastasis: Recent Updates. Cancers 2021, 13, 4590. [CrossRef] [PubMed]

5. Hasselgren, K.; Rosok, B.I.; Larsen, P.N.; Sparrelid, E.; Lindell, G.; Schultz, N.A.; Bjornbeth, B.A.; Isaksson, B.; Larsson, A.L.; Rizell, M.; et al. ALPPS Improves Survival Compared With TSH in Patients Affected of CRLM: Survival Analysis From the Randomized Controlled Trial LIGRO. Ann. Surg. 2021, 273, 442-448. [CrossRef] [PubMed]

6. Dueland, S.; Yaqub, S.; Syversveen, T.; Carling, U.; Hagness, M.; Brudvik, K.W.; Line, P.D. Survival Outcomes After Portal Vein Embolization and Liver Resection Compared With Liver Transplant for Patients With Extensive Colorectal Cancer Liver Metastases. JAMA Surg. 2021, 156, 550-557. [CrossRef]

7. Helling, T.S.; Martin, M. Cause of death from liver metastases in colorectal cancer. Ann. Surg. Oncol. 2014, 21, 501-506. [CrossRef]

8. Creasy, J.M.; Sadot, E.; Koerkamp, B.G.; Chou, J.F.; Gonen, M.; Kemeny, N.E.; Balachandran, V.P.; Kingham, T.P.; DeMatteo, R.P.; Allen, P.J.; et al. Actual 10-year survival after hepatic resection of colorectal liver metastases: What factors preclude cure? Surgery 2018, 163, 1238-1244. [CrossRef] [PubMed]

9. Sa Cunha, A.; Laurent, C.; Rault, A.; Couderc, P.; Rullier, E.; Saric, J. A second liver resection due to recurrent colorectal liver metastases. Arch. Surg. 2007, 142, 1144-1149; discussion 1150. [CrossRef]

10. Krell, R.W.; Reames, B.N.; Hendren, S.; Frankel, T.L.; Pawlik, T.M.; Chung, M.; Kwon, D.; Wong, S.L. Surgical Referral for Colorectal Liver Metastases: A Population-Based Survey. Ann. Surg. Oncol. 2015, 22, 2179-2194. [CrossRef]

11. Mohammad, W.M.; Martel, G.; Mimeault, R.; Fairfull-Smith, R.J.; Auer, R.C.; Balaa, F.K. Evaluating agreement regarding the resectability of colorectal liver metastases: A national case-based survey of hepatic surgeons. HPB Oxf. $2012,14,291-297$. [CrossRef]

12. Homayounfar, K.; Bleckmann, A.; Helms, H.J.; Lordick, F.; Ruschoff, J.; Conradi, L.C.; Sprenger, T.; Ghadimi, M.; Liersch, T. Discrepancies between medical oncologists and surgeons in assessment of resectability and indication for chemotherapy in patients with colorectal liver metastases. Br. J. Surg. 2014, 101, 550-557. [CrossRef] [PubMed]

13. Choti, M.A.; Thomas, M.; Wong, S.L.; Eaddy, M.; Pawlik, T.M.; Hirose, K.; Weiss, M.J.; Kish, J.; Green, M.R. Surgical Resection Preferences and Perceptions among Medical Oncologists Treating Liver Metastases from Colorectal Cancer. Ann. Surg. Oncol. 2016, 23, 375-381. [CrossRef] [PubMed]

14. D'Angelica, M.I.; Kemeny, N.E. Metastatic Colorectal Cancer to the Liver: Involve the Surgeon Early and Often. Ann. Surg. Oncol. 2015, 22, 2104-2106. [CrossRef] [PubMed]

15. Wei, A.C.; Jarnagin, W.R. Questioning Why More Patients with Colorectal Liver Metastases Are Not Referred for Metastasectomy. JAMA Surg. 2020, 155, 909-910. [CrossRef] [PubMed]

16. Hellingman, T.; de Swart, M.E.; Joosten, J.J.A.; Meijerink, M.R.; de Vries, J.J.J.; de Waard, J.W.D.; van Zweeden, A.A.; Zonderhuis, B.M.; Kazemier, G. The value of a dedicated multidisciplinary expert panel to assess treatment strategy in patients suffering from colorectal cancer liver metastases. Surg. Oncol. 2020, 35, 412-417. [CrossRef] [PubMed]

17. Giuliante, F.; Vigano, L.; De Rose, A.M.; Mirza, D.F.; Lapointe, R.; Kaiser, G.; Barroso, E.; Ferrero, A.; Isoniemi, H.; Lopez-Ben, S.; et al. Liver-First Approach for Synchronous Colorectal Metastases: Analysis of 7360 Patients from the LiverMetSurvey Registry. Ann. Surg. Oncol. 2021, 28, 8198-8208. [CrossRef] [PubMed]

18. Nordlinger, B.; Sorbye, H.; Glimelius, B.; Poston, G.J.; Schlag, P.M.; Rougier, P.; Bechstein, W.O.; Primrose, J.N.; Walpole, E.T.; Finch-Jones, M.; et al. Perioperative FOLFOX4 chemotherapy and surgery versus surgery alone for resectable liver metastases from colorectal cancer (EORTC 40983): Long-term results of a randomised, controlled, phase 3 trial. Lancet Oncol. 2013, 14, 1208-1215. [CrossRef] 
19. Kanemitsu, Y.; Shimizu, Y.; Mizusawa, J.; Inaba, Y.; Hamaguchi, T.; Shida, D.; Ohue, M.; Komori, K.; Shiomi, A.; Shiozawa, M.; et al. Hepatectomy Followed by mFOLFOX6 Versus Hepatectomy Alone for Liver-Only Metastatic Colorectal Cancer (JCOG0603): A Phase II or III Randomized Controlled Trial. J. Clin. Oncol. 2021, 39, 3789-3799. [CrossRef]

20. Uhlig, J.; Lukovic, J.; Dawson, L.A.; Patel, R.A.; Cavnar, M.J.; Kim, H.S. Locoregional Therapies for Colorectal Cancer Liver Metastases: Options Beyond Resection. Am. Soc. Clin. Oncol. Educ. Book 2021, 41, 133-146. [CrossRef]

21. Li, J.; Yuan, Y.; Yang, F.; Wang, Y.; Zhu, X.; Wang, Z.; Zheng, S.; Wan, D.; He, J.; Wang, J.; et al. Expert consensus on multidisciplinary therapy of colorectal cancer with lung metastases (2019 edition). J. Hematol. Oncol. 2019, 12, 16. [CrossRef]

22. Hong, N.J.; Wright, F.C.; Gagliardi, A.R.; Paszat, L.F. Examining the potential relationship between multidisciplinary cancer care and patient survival: An international literature review. J. Surg. Oncol. 2010, 102, 125-134. [CrossRef]

23. Oxenberg, J.; Papenfuss, W.; Esemuede, I.; Attwood, K.; Simunovic, M.; Kuvshinoff, B.; Francescutti, V. Multidisciplinary cancer conferences for gastrointestinal malignancies result in measureable treatment changes: A prospective study of 149 consecutive patients. Ann. Surg. Oncol. 2015, 22, 1533-1539. [CrossRef]

24. Osterlund, P.; Salminen, T.; Soveri, L.M.; Kallio, R.; Kellokumpu, I.; Lamminmaki, A.; Halonen, P.; Ristamaki, R.; Lantto, E.; Uutela, A.; et al. Repeated centralized multidisciplinary team assessment of resectability, clinical behavior, and outcomes in 1086 Finnish metastatic colorectal cancer patients (RAXO): A nationwide prospective intervention study. Lancet Reg. Health Eur. 2021, 3, 100049. [CrossRef]

25. Nordlinger, B.; Guiguet, M.; Vaillant, J.C.; Balladur, P.; Boudjema, K.; Bachellier, P.; Jaeck, D. Surgical resection of colorectal carcinoma metastases to the liver. A prognostic scoring system to improve case selection, based on 1568 patients. Association Francaise de Chirurgie. Cancer 1996, 77, 1254-1262. [CrossRef]

26. Fong, Y.; Fortner, J.; Sun, R.L.; Brennan, M.F.; Blumgart, L.H. Clinical score for predicting recurrence after hepatic resection for metastatic colorectal cancer: Analysis of 1001 consecutive cases. Ann. Surg. 1999, 230, 309-318; discussion 318-321. [CrossRef] [PubMed]

27. Rees, M.; Tekkis, P.P.; Welsh, F.K.; O'Rourke, T.; John, T.G. Evaluation of long-term survival after hepatic resection for metastatic colorectal cancer: A multifactorial model of 929 patients. Ann. Surg. 2008, 247, 125-135. [CrossRef] [PubMed]

28. Brudvik, K.W.; Passot, G.; Vauthey, J.N. Colorectal Liver Metastases: A Changing Treatment Landscape. J. Oncol. Pract. 2016, 12, 40-41. [CrossRef] [PubMed]

29. Dijkstra, M.; Nieuwenhuizen, S.; Puijk, R.S.; Timmer, F.E.F.; Geboers, B.; Schouten, E.A.C.; Opperman, J.; Scheffer, H.J.; de Vries, J.J.J.; Versteeg, K.S.; et al. Primary Tumor Sidedness, RAS and BRAF Mutations and MSI Status as Prognostic Factors in Patients with Colorectal Liver Metastases Treated with Surgery and Thermal Ablation: Results from the Amsterdam Colorectal Liver Met Registry (AmCORE). Biomedicines 2021, 9, 962. [CrossRef]

30. Charnsangavej, C.; Clary, B.; Fong, Y.; Grothey, A.; Pawlik, T.M.; Choti, M.A. Selection of patients for resection of hepatic colorectal metastases: Expert consensus statement. Ann. Surg. Oncol. 2006, 13, 1261-1268. [CrossRef]

31. Kaczirek, K. ASCO 2016-update colorectal liver metastases. Memo 2017, 10, 103-105. [CrossRef]

32. Gonzalez, H.D.; Figueras, J. Practical questions in liver metastases of colorectal cancer: General principles of treatment. HPB Oxf. 2007, 9, 251-258. [CrossRef]

33. Adam, R.; Kitano, Y.; Abdelrafee, A.; Allard, M.A.; Baba, H. Debulking surgery for colorectal liver metastases: Foolish or chance? Surg. Oncol. 2020, 33, 266-269. [CrossRef] [PubMed]

34. Jo, H.S.; Kim, D.S.; Jung, S.W.; Yu, Y.D.; Choi, S.B.; Kim, W.B.; Han, H.J.; Song, T.J. Clinical significance of post-hepatectomy hepatic failure in patients with liver metastases from colorectal cancer. Ann. Hepatobiliary Pancreat Surg. 2018, 22, 93-100. [CrossRef] [PubMed]

35. van Vledder, M.G.; de Jong, M.C.; Pawlik, T.M.; Schulick, R.D.; Diaz, L.A.; Choti, M.A. Disappearing colorectal liver metastases after chemotherapy: Should we be concerned? J. Gastrointest Surg. 2010, 14, 1691-1700. [CrossRef] [PubMed]

36. Kuhlmann, K.; van Hilst, J.; Fisher, S.; Poston, G. Management of disappearing colorectal liver metastases. Eur. J. Surg. Oncol. 2016, 42, 1798-1805. [CrossRef]

37. Araujo, R.L.C.; Milani, J.M.; Armentano, D.P.; Moreira, R.B.; Pinto, G.S.F.; de Castro, L.A.; Lucchesi, F.R. Disappearing colorectal liver metastases: Strategies for the management of patients achieving a radiographic complete response after systemic chemotherapy. J. Surg. Oncol. 2020, 121, 848-856. [CrossRef]

38. Benoist, S.; Brouquet, A.; Penna, C.; Julie, C.; El Hajjam, M.; Chagnon, S.; Mitry, E.; Rougier, P.; Nordlinger, B. Complete response of colorectal liver metastases after chemotherapy: Does it mean cure? J. Clin. Oncol. 2006, 24, 3939-3945. [CrossRef]

39. Tani, K.; Shindoh, J.; Akamatsu, N.; Arita, J.; Kaneko, J.; Sakamoto, Y.; Hasegawa, K.; Kokudo, N. Management of disappearing lesions after chemotherapy for colorectal liver metastases: Relation between detectability and residual tumors. J. Surg. Oncol. 2018, 117, 191-197. [CrossRef]

40. Oba, A.; Mise, Y.; Ito, H.; Hiratsuka, M.; Inoue, Y.; Ishizawa, T.; Arita, J.; Matsueda, K.; Takahashi, Y.; Saiura, A. Clinical implications of disappearing colorectal liver metastases have changed in the era of hepatocyte-specific MRI and contrast-enhanced intraoperative ultrasonography. HPB Oxf. 2018, 20, 708-714. [CrossRef]

41. Hoffmann, K.; Nagel, A.J.; Tanabe, K.; Fuchs, J.; Dehlke, K.; Ghamarnejad, O.; Lemekhova, A.; Mehrabi, A. Markers of liver regeneration-the role of growth factors and cytokines: A systematic review. BMC Surg. 2020, 20, 31. [CrossRef]

42. Ramadori, G.; Cameron, S. Effects of systemic chemotherapy on the liver. Ann. Hepatol. 2010, 9, 133-143. [CrossRef] 
43. Khan, A.S.; Garcia-Aroz, S.; Ansari, M.A.; Atiq, S.M.; Senter-Zapata, M.; Fowler, K.; Doyle, M.B.; Chapman, W.C. Assessment and optimization of liver volume before major hepatic resection: Current guidelines and a narrative review. Int. J. Surg. 2018, 52, 74-81. [CrossRef] [PubMed]

44. Jarnagin, W.R.; Belghiti, J.; Blumgart, L.H. Blumgart's Surgery for the Liver, Biliary Tract, and Pancreas, 6th ed.; Elsevier Saunders: Philadelphia, PA, USA, 2017.

45. Choi, S.H.; Kim, S.Y.; Park, S.H.; Kim, K.W.; Lee, J.Y.; Lee, S.S.; Lee, M.G. Diagnostic performance of CT, gadoxetate disodiumenhanced MRI, and PET/CT for the diagnosis of colorectal liver metastasis: Systematic review and meta-analysis. J. Magn. Reson. Imaging 2018, 47, 1237-1250. [CrossRef] [PubMed]

46. Mao, Y.; Chen, B.; Wang, H.; Zhang, Y.; Yi, X.; Liao, W.; Zhao, L. Diagnostic performance of magnetic resonance imaging for colorectal liver metastasis: A systematic review and meta-analysis. Sci. Rep. 2020, 10, 1969. [CrossRef] [PubMed]

47. Moulton, C.A.; Gu, C.S.; Law, C.H.; Tandan, V.R.; Hart, R.; Quan, D.; Fairfull Smith, R.J.; Jalink, D.W.; Husien, M.; Serrano, P.E.; et al. Effect of PET before liver resection on surgical management for colorectal adenocarcinoma metastases: A randomized clinical trial. JAMA 2014, 311, 1863-1869. [CrossRef]

48. Villard, C.; Habib, M.; Nordenvall, C.; Nilsson, P.J.; Jorns, C.; Sparrelid, E. Conversion therapy in patients with colorectal liver metastases. Eur. J. Surg. Oncol. 2021, 47, 2038-2045. [CrossRef]

49. Datta, J.; Narayan, R.R.; Kemeny, N.E.; D'Angelica, M.I. Role of Hepatic Artery Infusion Chemotherapy in Treatment of Initially Unresectable Colorectal Liver Metastases: A Review. JAMA Surg. 2019, 154, 768-776. [CrossRef]

50. Adam, R.; de Gramont, A.; Figueras, J.; Kokudo, N.; Kunstlinger, F.; Loyer, E.; Poston, G.; Rougier, P.; Rubbia-Brandt, L.; Sobrero, A.; et al. Managing synchronous liver metastases from colorectal cancer: A multidisciplinary international consensus. Cancer Treat. Rev. 2015, 41, 729-741. [CrossRef]

51. Manfredi, S.; Lepage, C.; Hatem, C.; Coatmeur, O.; Faivre, J.; Bouvier, A.M. Epidemiology and management of liver metastases from colorectal cancer. Ann. Surg. 2006, 244, 254-259. [CrossRef]

52. Okholm, C.; Mollerup, T.K.; Schultz, N.A.; Strandby, R.B.; Achiam, M.P. Synchronous and metachronous liver metastases in patients with colorectal cancer. Dan. Med. J. 2018, 65, A5524.

53. Vayrynen, V.; Wirta, E.V.; Seppala, T.; Sihvo, E.; Mecklin, J.P.; Vasala, K.; Kellokumpu, I. Incidence and management of patients with colorectal cancer and synchronous and metachronous colorectal metastases: A population-based study. BJS Open 2020, 4, 685-692. [CrossRef]

54. Schlag, P.M.; Benhidjeb, T.; Stroszczynski, C. Resection and local therapy for liver metastases. Best Pract. Res. Clin. Gastroenterol. 2002, 16, 299-317. [CrossRef] [PubMed]

55. Modest, D.P.; Pant, S.; Sartore-Bianchi, A. Treatment sequencing in metastatic colorectal cancer. Eur. J. Cancer 2019, 109, 70-83. [CrossRef] [PubMed]

56. Brouquet, A.; Mortenson, M.M.; Vauthey, J.N.; Rodriguez-Bigas, M.A.; Overman, M.J.; Chang, G.J.; Kopetz, S.; Garrett, C.; Curley, S.A.; Abdalla, E.K. Surgical strategies for synchronous colorectal liver metastases in 156 consecutive patients: Classic, combined or reverse strategy? J. Am. Coll. Surg. 2010, 210, 934-941. [CrossRef] [PubMed]

57. de Jong, M.C.; Beckers, R.C.J.; van Woerden, V.; Sijmons, J.M.L.; Bemelmans, M.H.A.; van Dam, R.M.; Dejong, C.H.C. The liver-first approach for synchronous colorectal liver metastases: More than a decade of experience in a single centre. $H P B O x f$. 2018, 20, 631-640. [CrossRef]

58. Mentha, G.; Majno, P.E.; Andres, A.; Rubbia-Brandt, L.; Morel, P.; Roth, A.D. Neoadjuvant chemotherapy and resection of advanced synchronous liver metastases before treatment of the colorectal primary. Br. J. Surg. 2006, 93, 872-878. [CrossRef]

59. Gavriilidis, P.; Katsanos, K.; Sutcliffe, R.P.; Simopoulos, C.; Azoulay, D.; Roberts, K.J. Simultaneous, Delayed and Liver-First Hepatic Resections for Synchronous Colorectal Liver Metastases: A Systematic Review and Network Meta-Analysis. J. Clin. Med. Res. 2019, 11, 572-582. [CrossRef]

60. Nordlinger, B.; Sorbye, H.; Glimelius, B.; Poston, G.J.; Schlag, P.M.; Rougier, P.; Bechstein, W.O.; Primrose, J.N.; Walpole, E.T.; Finch-Jones, M.; et al. Perioperative chemotherapy with FOLFOX4 and surgery versus surgery alone for resectable liver metastases from colorectal cancer (EORTC Intergroup trial 40983): A randomised controlled trial. Lancet 2008, 371, 1007-1016. [CrossRef]

61. Hsu, H.T.; Wu, L.M.; Lin, P.C.; Juan, C.H.; Huang, Y.Y.; Chou, P.L.; Chen, J.L. Emotional distress and quality of life during folinic acid, fluorouracil, and oxaliplatin in colorectal cancer patients with and without chemotherapy-induced peripheral neuropathy: A cross-sectional study. Med. Baltim. 2020, 99, e19029. [CrossRef]

62. Saltz, L.B. Progress in cancer care: The hope, the hype, and the gap between reality and perception. J. Clin. Oncol. 2008, 26, 5020-5021. [CrossRef]

63. White, R.R.; Schwartz, L.H.; Munoz, J.A.; Raggio, G.; Jarnagin, W.R.; Fong, Y.; D’Angelica, M.I.; Kemeny, N.E. Assessing the optimal duration of chemotherapy in patients with colorectal liver metastases. J. Surg. Oncol. 2008, 97, 601-604. [CrossRef]

64. Chen, Q.; Li, X.; Zhao, J.; Bi, X.; Li, Z.; Huang, Z.; Zhang, Y.; Zhou, J.; Zhao, H.; Cai, J. What is the optimal number of neoadjuvant chemotherapy cycles for resectable colorectal liver oligometastases? Ann. Transl. Med. 2021, 9, 7. [CrossRef]

65. Robinson, S.M.; Wilson, C.H.; Burt, A.D.; Manas, D.M.; White, S.A. Chemotherapy-associated liver injury in patients with colorectal liver metastases: A systematic review and meta-analysis. Ann. Surg. Oncol. 2012, 19, 4287-4299. [CrossRef] [PubMed]

66. Karoui, M.; Penna, C.; Amin-Hashem, M.; Mitry, E.; Benoist, S.; Franc, B.; Rougier, P.; Nordlinger, B. Influence of preoperative chemotherapy on the risk of major hepatectomy for colorectal liver metastases. Ann. Surg. 2006, 243, 1-7. [CrossRef] [PubMed] 
67. Morris-Stiff, G.; Tan, Y.M.; Vauthey, J.N. Hepatic complications following preoperative chemotherapy with oxaliplatin or irinotecan for hepatic colorectal metastases. Eur. J. Surg. Oncol. 2008, 34, 609-614. [CrossRef] [PubMed]

68. Sutherland, F.; Harris, J. Claude Couinaud: A passion for the liver. Arch. Surg. 2002, 137, 1305-1310. [CrossRef]

69. Man, K.; Fan, S.T.; Ng, I.O.; Lo, C.M.; Liu, C.L.; Wong, J. Prospective evaluation of Pringle maneuver in hepatectomy for liver tumors by a randomized study. Ann. Surg. 1997, 226, 704-711. [CrossRef]

70. Melendez, J.A.; Arslan, V.; Fischer, M.E.; Wuest, D.; Jarnagin, W.R.; Fong, Y.; Blumgart, L.H. Perioperative outcomes of major hepatic resections under low central venous pressure anesthesia: Blood loss, blood transfusion, and the risk of postoperative renal dysfunction. J. Am. Coll. Surg. 1998, 187, 620-625. [CrossRef]

71. Andreou, A.; Gloor, S.; Inglin, J.; Di Pietro Martinelli, C.; Banz, V.; Lachenmayer, A.; Kim-Fuchs, C.; Candinas, D.; Beldi, G. Parenchymal-sparing hepatectomy for colorectal liver metastases reduces postoperative morbidity while maintaining equivalent oncologic outcomes compared to non-parenchymal-sparing resection. Surg. Oncol. 2021, 38, 101631. [CrossRef]

72. Mise, Y.; Aloia, T.A.; Brudvik, K.W.; Schwarz, L.; Vauthey, J.N.; Conrad, C. Parenchymal-sparing Hepatectomy in Colorectal Liver Metastasis Improves Salvageability and Survival. Ann. Surg. 2016, 263, 146-152. [CrossRef]

73. Wong, L.H.; Sutton, T.L.; Walker, B.S.; Lopez, C.D.; Kardosh, A.; Eil, R.L.; Chen, E.Y.; Billingsley, K.G.; Mayo, S.C. Surgical and oncologic outcomes following repeat hepatic resection of colorectal liver metastasis: Who benefits? Am. J. Surg. 2021, 221, 1114-1118. [CrossRef]

74. Torzilli, G.; Vigano, L.; Cimino, M.; Imai, K.; Vibert, E.; Donadon, M.; Mansour, D.; Castaing, D.; Adam, R. Is Enhanced One-Stage Hepatectomy a Safe and Feasible Alternative to the Two-Stage Hepatectomy in the Setting of Multiple Bilobar Colorectal Liver Metastases? A Comparative Analysis between Two Pioneering Centers. Dig. Surg. 2018, 35, 323-332. [CrossRef]

75. Torzilli, G.; Serenari, M.; Vigano, L.; Cimino, M.; Benini, C.; Massani, M.; Ettorre, G.M.; Cescon, M.; Ferrero, A.; Cillo, U.; et al Outcomes of enhanced one-stage ultrasound-guided hepatectomy for bilobar colorectal liver metastases compared to those of ALPPS: A multicenter case-match analysis. HPB Oxf. 2019, 21, 1411-1418. [CrossRef]

76. DeMatteo, R.P.; Palese, C.; Jarnagin, W.R.; Sun, R.L.; Blumgart, L.H.; Fong, Y. Anatomic segmental hepatic resection is superior to wedge resection as an oncologic operation for colorectal liver metastases. J. Gastrointest Surg. 2000, 4, 178-184. [CrossRef]

77. Tang, H.; Li, B.; Zhang, H.; Dong, J.; Lu, W. Comparison of Anatomical and Nonanatomical Hepatectomy for Colorectal Liver Metastasis: A Meta-Analysis of 5207 Patients. Sci. Rep. 2016, 6, 32304. [CrossRef]

78. Adam, R.; Laurent, A.; Azoulay, D.; Castaing, D.; Bismuth, H. Two-stage hepatectomy: A planned strategy to treat irresectable liver tumors. Ann. Surg. 2000, 232, 777-785. [CrossRef]

79. Chavez, M.I.; Gholami, S.; Kim, B.J.; Margonis, G.A.; Ethun, C.G.; Tsai, S.; Christians, K.K.; Clarke, C.; Mogal, H.; Maithel, S.K.; et al. Two-Stage Hepatectomy for Bilateral Colorectal Liver Metastases: A Multi-institutional Analysis. Ann. Surg. Oncol. 2021, 28, 1457-1465. [CrossRef] [PubMed]

80. Sandstrom, P.; Rosok, B.I.; Sparrelid, E.; Larsen, P.N.; Larsson, A.L.; Lindell, G.; Schultz, N.A.; Bjornbeth, B.A.; Isaksson, B.; Rizell, M.; et al. ALPPS Improves Resectability Compared With Conventional Two-stage Hepatectomy in Patients With Advanced Colorectal Liver Metastasis: Results From a Scandinavian Multicenter Randomized Controlled Trial (LIGRO Trial). Ann. Surg. 2018, 267, 833-840. [CrossRef]

81. Simoneau, E.; D’Angelica, M.; Halazun, K.J. Liver transplantation for colorectal liver metastasis. Curr. Opin. Organ. Transpl. 2019, 24, 175-181. [CrossRef] [PubMed]

82. Braun, H.J.; Roberts, J.P. Current status of left lobe adult to adult living donor liver transplantation. Curr. Opin. Organ. Transpl. 2021, 26, 139-145. [CrossRef]

83. Bonney, G.K.; Chew, C.A.; Lodge, P.; Hubbard, J.; Halazun, K.J.; Trunecka, P.; Muiesan, P.; Mirza, D.F.; Isaac, J.; Laing, R.W.; et al. Liver transplantation for non-resectable colorectal liver metastases: The International Hepato-Pancreato-Biliary Association consensus guidelines. Lancet Gastroenterol. Hepatol. 2021, 6, 933-946. [CrossRef]

84. Ensminger, W.D.; Rosowsky, A.; Raso, V.; Levin, D.C.; Glode, M.; Come, S.; Steele, G.; Frei, E., 3rd. A clinical-pharmacological evaluation of hepatic arterial infusions of 5-fluoro-2'-deoxyuridine and 5-fluorouracil. Cancer Res. 1978, 38, 3784-3792. [PubMed]

85. Collins, J.M. Pharmacologic rationale for regional drug delivery. J. Clin. Oncol. 1984, 2, 498-504. [CrossRef]

86. Buisman, F.E.; Filipe, W.F.; Kemeny, N.E.; Narayan, R.R.; Srouji, R.M.; Balachandran, V.P.; Boerner, T.; Drebin, J.A.; Jarnagin, W.R.; Kingham, T.P.; et al. Recurrence After Liver Resection of Colorectal Liver Metastases: Repeat Resection or Ablation Followed by Hepatic Arterial Infusion Pump Chemotherapy. Ann. Surg. Oncol. 2021, 28, 808-816. [CrossRef] [PubMed]

87. Buisman, F.E.; Filipe, W.F.; Galjart, B.; Grunhagen, D.J.; Homs, M.Y.V.; Moelker, A.; Verhoef, C.; Groot Koerkamp, B. Adjuvant intra-arterial chemotherapy for patients with resected colorectal liver metastases: A systematic review and meta-analysis. $H P B$ Oxf. 2021. [CrossRef] [PubMed]

88. Kingham, T.P.; D'Angelica, M.; Kemeny, N.E. Role of intra-arterial hepatic chemotherapy in the treatment of colorectal cancer metastases. J. Surg. Oncol. 2010, 102, 988-995. [CrossRef]

89. Lam, V.W.; Spiro, C.; Laurence, J.M.; Johnston, E.; Hollands, M.J.; Pleass, H.C.; Richardson, A.J. A systematic review of clinical response and survival outcomes of downsizing systemic chemotherapy and rescue liver surgery in patients with initially unresectable colorectal liver metastases. Ann. Surg. Oncol. 2012, 19, 1292-1301. [CrossRef] [PubMed]

90. Kelly, C.M.; Kemeny, N.E. Liver-directed therapy in metastatic colorectal cancer. Expert. Rev. Anticancer Ther. 2017, 17, 745-758. [CrossRef] [PubMed] 
91. Kemeny, N.E.; Melendez, F.D.; Capanu, M.; Paty, P.B.; Fong, Y.; Schwartz, L.H.; Jarnagin, W.R.; Patel, D.; D’Angelica, M. Conversion to resectability using hepatic artery infusion plus systemic chemotherapy for the treatment of unresectable liver metastases from colorectal carcinoma. J. Clin. Oncol. 2009, 27, 3465-3471. [CrossRef] [PubMed]

92. Pak, L.M.; Kemeny, N.E.; Capanu, M.; Chou, J.F.; Boucher, T.; Cercek, A.; Balachandran, V.P.; Kingham, T.P.; Allen, P.J.; DeMatteo, R.P.; et al. Prospective phase II trial of combination hepatic artery infusion and systemic chemotherapy for unresectable colorectal liver metastases: Long term results and curative potential. J. Surg. Oncol. 2018, 117, 634-643. [CrossRef] [PubMed]

93. Yamasaki, T.; Saeki, I.; Kotoh-Yamauchi, Y.; Sasaki, R.; Tanabe, N.; Oono, T.; Matsuda, T.; Hisanaga, T.; Matsumoto, T.; Hidaka, I.; et al. Clinical Benefits of Hepatic Arterial Infusion Chemotherapy for Advanced Hepatocellular Carcinoma. Appl. Sci. 2021, 11, 1882. [CrossRef]

94. Chaudhry, S.; Fields, R.C.; Grierson, P.M.; Lim, K.-H. Combined Systemic and Hepatic Artery Infusion Pump Chemo-Therapy as a Liver-Directed Therapy for Colorectal Liver Metastasis-Review of Literature and Case Discussion. Cancers 2021, 13, 1283. [CrossRef]

95. Ahmad, A.; Chen, S.L.; Bilchik, A.J. Role of repeated hepatectomy in the multimodal treatment of hepatic colorectal metastases. Arch. Surg. 2007, 142, 526-531. [CrossRef]

96. Battula, N.; Tsapralis, D.; Mayer, D.; Isaac, J.; Muiesan, P.; Sutcliffe, R.P.; Bramhall, S.; Mirza, D.; Marudanayagam, R. Repeat liver resection for recurrent colorectal metastases: A single-centre, 13-year experience. HPB Oxf. 2014, 16, 157-163. [CrossRef]

97. Rocca, A.; Scacchi, A.; Cappuccio, M.; Avella, P.; Bugiantella, W.; De Rosa, M.; Costa, G.; Polistena, A.; Codacci-Pisanelli, M.; Amato, B.; et al. Robotic surgery for colorectal liver metastases resection: A systematic review. Int. J. Med. Robot. 2021, 17, e2330. [CrossRef]

98. Wakabayashi, G.; Cherqui, D.; Geller, D.A.; Buell, J.F.; Kaneko, H.; Han, H.S.; Asbun, H.; O’Rourke, N.; Tanabe, M.; Koffron, A.J.; et al. Recommendations for laparoscopic liver resection: A report from the second international consensus conference held in Morioka. Ann. Surg. 2015, 261, 619-629. [CrossRef]

99. Cho, J.Y.; Han, H.S.; Wakabayashi, G.; Soubrane, O.; Geller, D.; O’Rourke, N.; Buell, J.; Cherqui, D. Practical guidelines for performing laparoscopic liver resection based on the second international laparoscopic liver consensus conference. Surg. Oncol. 2018, 27, A5-A9. [CrossRef] [PubMed]

100. Beppu, T.; Wakabayashi, G.; Hasegawa, K.; Gotohda, N.; Mizuguchi, T.; Takahashi, Y.; Hirokawa, F.; Taniai, N.; Watanabe, M.; Katou, M.; et al. Long-term and perioperative outcomes of laparoscopic versus open liver resection for colorectal liver metastases with propensity score matching: A multi-institutional Japanese study. J. Hepatobiliary Pancreat Sci. 2015, 22, 711-720. [CrossRef] [PubMed]

101. Ceccarelli, G.; Rocca, A.; De Rosa, M.; Fontani, A.; Ermili, F.; Andolfi, E.; Bugiantella, W.; Levi Sandri, G.B. Minimally invasive robotic-assisted combined colorectal and liver excision surgery: Feasibility, safety and surgical technique in a pilot series. Updates Surg. 2021, 73, 1015-1022. [CrossRef] [PubMed] 